\title{
Ascorbic acid has superior antiviral and antiproliferative effects over IFN-alpha in HAM/TSP PBMC ex vivo
}

\author{
Britta Moens ${ }^{1 *}$, Daniele Decanine ${ }^{2}$, Ricardo Khouri ${ }^{1}$, Giovanni Lopez ${ }^{3}$, Michael Talledo ${ }^{3}$, Eduardo Gotuzzo ${ }^{3,4}$, \\ Françoise Bex ${ }^{5}$, Bernardo Galvão Castro ${ }^{2}$, Anne-Mieke Vandamme ${ }^{1}$, Johan Van Weyenbergh ${ }^{1,2}$
}

From 15th International Conference on Human Retroviruses: HTLV and Related Viruses

Leuven and Gembloux, Belgium. 5-8 June 2011

IFN-alpha and high dose ascorbic acid (AA) have a modest clinical benefit in HAM/TSP (Nakagawa, 1996). We investigated the effect of ex vivo and in vitro AA and IFN-alpha treatment on HAM/TSP PBMC and HTLV-1-infected cell lines, respectively.

We treated cells for $48-72 \mathrm{~h}$ ex vivo and in vitro with low-high $(10-100 \mu \mathrm{g} / \mathrm{ml})$ dose of AA and $1000 \mathrm{U} / \mathrm{ml}$ of IFN-alpha and quantified lymphoproliferation by $\left[{ }^{3} \mathrm{H}\right]$ thymidine incorporation, tetraploid DNA content and PCNA expression (flow cytometry). Viral expression was measured at the RNA (tax, LTR) and protein (Tax, p19) level by RT-PCR, Western blot and ELISA, respectively. Apoptosis was quantified by subdiploid DNA content (flow cytometry). Th1/Th2/Th17 cytokines were quantified by cytometric bead array. AA induced a dramatic $95 \%$ decrease (control $3689 \pm 755 \mathrm{cpm}$ vs. AA $121 \pm 52$ $\mathrm{cpm}, \mathrm{p}=0.001$ ) in spontaneous, virus-driven lymphoproliferation and a decrease in tax and LTR transcription in HAM/TSP PBMC. In addition, AA decreased the exacerbated ex vivo IFN-gamma production in HAM/TSP PBMC. In HTLV-1 infected cell lines (MT-2 and MT4), AA induced a dose-dependent increase in DNA fragmentation $(\mathrm{p}=0.02, \mathrm{p}=0.005)$, paralleled by a decrease in PCNA $(\mathrm{p}=0.003)$, as well as $\mathrm{p} 19(\mathrm{p}<0.001)$ and Tax levels. These effects appear virus-specific, since highdose $(100 \mu \mathrm{g} / \mathrm{ml})$ AA did not exert a significant antiproliferative or pro-apoptotic effect on PBMC of normal donors. On top, AA displayed a superior antiprolifera- tive, antiviral and immunomodulatory effect over IFNalpha in both cell lines and HAM/TSP PBMC. Considering the selective antiproliferative and antiviral effects of AA ex vivo and in vitro, the therapeutic potential of combination therapy with high dose AA in HAM/TSP should be further explored.

\section{Author details}

'Laboratory of Clinical and Epidemiological Virology, Rega Institute for Medical Research K.U. Leuven, Leuven, Belgium. ${ }^{2}$ Gonçalo Moniz Research Center, Oswaldo Cruz Foundation (FIOCRUZ), Salvador-Bahia, Brazil. Instituto de Medicina Tropical Alexander von Humboldt, Universidad Peruana Cayetano Heredia, Lima, Peru. ${ }^{4}$ Departamento de Medicina, Facultad de Medicina, Universidad Peruana Cayetano Heredia, Lima, Peru. Institute for Microbiological Research J-M Wiame and Laboratory of Microbiology, Université Libre de Bruxelles, Bruxelles, Belgium.

Published: 6 June 2011

\section{Reference}

1. Nakagawa M, Nakahara K, Maruyama Y, Kawabata M, Higuchi I, Kubota H, Izumo S, Arimura K, Osame M: Therapeutic trials in 200 patients with HTLV-I-associated myelopathy/tropical spastic paraparesis. J Neurovirol 1996, 2:345-355.

doi:10.1186/1742-4690-8-S1-A61

Cite this article as: Moens et al: Ascorbic acid has superior antiviral and antiproliferative effects over IFN-alpha in HAM/TSP PBMC ex vivo. Retrovirology 2011 8(Suppl 1):A61.

\footnotetext{
* Correspondence: britta.moens@rega.kuleuven.be

'Laboratory of Clinical and Epidemiological Virology, Rega Institute for

Medical Research K.U. Leuven, Leuven, Belgium

Full list of author information is available at the end of the article
}

๑ 2011 Moens et al; licensee BioMed Central Ltd. This is an open access article distributed under the terms of the Creative Commons 